\title{
Snoezelen terapia: zazpi funtsezko zentzumenen ahalmena
}

\author{
Snoezelen therapy: the power of the seven senses \\ ${ }^{1,2}$ Irantzu Rico-Barrio, ${ }^{3}$ Janire Rojas, ${ }^{1,2}$ Ianire Buceta, ${ }^{1,2}$ Nagore Puente, ${ }^{1,2}$ Maitane Serrano \\ eta ${ }^{1,2}$ Pedro Grandes \\ ${ }^{1}$ Neurozientziak Saila, Medikuntza eta Erizaintza Fakultatea, Euskal Herriko Unibertsitatea, \\ E-48940, Leioa, Bizkaia, Euskal Herria. \\ ${ }^{2}$ Achucarro Basque Center for Neuroscience, UPV/EHU Zientzia Parkea, E-48940, Leioa, \\ Bizkaia, Euskal Herria. \\ ${ }^{3}$ Terapia klinikoak-Errehabilitazioa Saila, International Snoezelen Association professional \\ e, V-ISNA Erakundea, Alemania. \\ irantzu.rico@ehu.eus
}

\section{Laburpena}

Snoezelen terapia, zentzumen anitzeko terapia (ZAT) ez-farmakologiko eta psikosoziala da; zazpi funtsezko zentzumenen estimulazioan edo erlaxazioan oinarritzen dena, hain zuzen ere. Pertsonon ongizatea eta norberaren bizi-kalitatea hobetzea du helburu nagusia. Ikusmen, entzumen, ukimen, dastamen, oreka, propriozepzio eta usaimen zentzumenak hainbat objekturen bitartez kitzikatzen dira: argiztapen artifizialaren, musika lasaigarri edo terapeutikoaren, ehundura ezberdinen eta hainbat lurrinen eta elikagaien bidez, besteak beste. Terapia honen erabilera dementziaren sintoma fisiologikoak eta portaera-aldaketak arintzeko hautabide eraginkor gisa bistaratu da azken hamarkadan. Dementzia etengabeko narriadura kognitiboa eragiten duen gaixotasun kronikoa eta atzeraezina da; baita sintoma fisiko, fisiologiko eta portaera-aldaketa nabarmenak eragiten dituen gaitz neurologikoa ere. Oldarkortasuna, depresioa, antsietatea, gogogabezia, loezina eta elikaduranahasmendua dira dementzia gaixotasunean deskribatu izan diren eta Snoezelen terapiak hobetzen dituen sintoma fisiologiko eta portaera-aldaketa ohikoenak. Horrez gain, aipatzekoak dira Rett sindromean, garun-lesio traumatikoan, zainketa aringarrietako programetan eta garun-paralisian Snoezelen terapiak eragiten dituen onura nabarmenak. Azterlan honek Snoezelen terapiaren inguruko hainbat ikerketa biltzen ditu. Kontzeptuaren deskribapen zehaztua eta Euskal Herriko udalerrietan azken urteotan terapia honi eman zaion erabilera terapeutikoaren zein pedagogikoaren azalpen orokorra azaltzen dira. Horrez gain, hainbat gaixotasunen aurrean terapia honek ekar ditzakeen efektu mesedegarrien edo mugen eta gabezien deskribapena jorratuko da ikuspuntu kritiko batetik.

Gako-hitzak: Snoezelen, zentzumenak, terapia, estimulazioa, erlaxazioa, dementzia.

\section{Abstract}

Snoezelen, a multi-sensory stimulation therapy described as a nonpharmacological psychosocial intervention, is based on the stimulation or relaxation of the primary senses of sight, hearing, touch, taste, balancing, proprioception and smell, through the use of lighting effects, meditative or integrative music, tactile surfaces, and the odors of relaxing essential oils. The main objective of this multi-sensory therapeutic approach is the personal wellbeing of people. It has become increasingly 
popular in the last decades given its efficacy to alleviate the behavioral and psychological (BPSD) symptoms usually observed and described in dementia illness. Dementia is a chronic, irreversible and neurological disease that is characterized by a progressive cognitive deterioration and a wide range of behavioral and psychosocial problems including aggression, depression, anxiety, euphoria, apathy, disinhibition, agitation, sleeping disturbances, and eating disorders. In addition, a few studies have also reported the possible application of this therapy in other diseases such as Rett syndrome, traumatic brain injury, palliative care or cerebral paralysis. This review collects Snoezelen information of various articles offering a detailed description of the concept. It also explains the pedagogical and therapeutic used of the therapy that is taking place in villages of the Basque Country, giving a critical view of the beneficial effects and shortcomings that Snoezelen therapy can bring for treating brain diseases.

Keywords: Snoezelen, senses, therapy, stimulation, relaxation, dementia.

Bidalia: 2019ko urtarrilaren 24an.

Onartua: 2019ko maiatzaren 21ean.

https://doi.org/10.26876/osagaiz.1.2019.230

\section{Sarrera: Snoezelen kontzeptuaren deskribapena}

Snoezelen elea nederlanderazko bi hitzen lotura da: "Snuffelen" eta "Doezelen" hitzak, hurrenez hurren. "Snuffelen" berbak aditu edo arakatu kontzeptuak barne hartzen ditu. "Doezelen" terminoak, berriz, erlaxamenduari edo lasaitasunari aipamena egiten dio (1). Snoezelen zentzumen anitzeko terapiaren (ZAT) ikuspegi bat da; 70eko hamarkadan Ad Verheul eta Jan Hulsegge terapeuta holandarrek sortutako zazpi zentzuak sakonki kitzikatzen edo erlaxatzen dituen terapia ezfarmakologiko iraultzailea, hain zuzen ere (2). Snoezelenek pertsonon bizi-kalitatea hobetzea du helburu nagusi. Hornikuntza bereziarekin zuzkitutako geletan gauzatzen da, eta funtsezko zazpi zentzumenen estimulazioa argiaren, soinuaren, hainbat ehunduren, lurrinen edo elikagaien bitartez bideratzen da (3). Musika lasaigarria edo terapeutikoa, aromaterapia, kolore ezberdinetako burbuilatutuak, ur-zutabeak, olio-esentziak, ispilu-bolak, zapore ezberdinetako jakiak, ikusmen-zuntzak, pantaila-proiektagailuak, masajeak, dardaragailuak eta ukimena garatzeko erremintak izaten dira 3045 minutuko saioetan geletan tresnatzen diren objektu ohikoenak; baita pazienteen esperientzia sentsorialak lantzeko eskaintzen diren tresna eraginkorrenak ere (4). Hori gutxi balitz, estimulu bakoitza isola, konbina, areagotu, murriztu eta molda daiteke, aldi oro gaixo bakoitzaren eskakizun zehatzari lehentasuna emanez eta banakako arreta lehenetsiz (5). Horrela, norberaren ongitasuna zein lasaitasuna arras bermatzen da.

Snoezelen espazioa, zentzumen-sistema bakoitza lantzeko erabiltzen diren usaiako elementuetan sailka daiteke:

- Ikusmen-estimulazioa: Snoezelen espazioek eskaini beharreko giro berezia dela bide, ikusmen elementuek garrantzi handia hartzen dute. Horrela, ispilu-bola birakariak, ikusmenzuntzek, burbuila-zutabeak, margo fluoreszenteek, esku-argiak eta argi-proiektagailuak atmosfera atsegingarria, bake-ingurugiroa eta lasaitasuna gauzatuko dituzte.

- Ukimen-estimulazioa: ehundura ezberdinetako jostailuek edo objektuek, elementu bibragailuek eta askotariko tenperaturen pertzepzioak ukimen-sentsazioa kitzikatzeko aukera emango dute.

- Bestibulu-estimulazioa: bestibulu-zentzumena Snoezelen geletan landu beharreko funtsezko zentzumena da. Batetik muskulu-tonuaren gutxipena lortzen du. Bestetik, pertsonaren erlaxazioa sustatzen du. Gaur egun bestibulu-estimulazioa lantzeko erabiltzen den aparaturik arruntena urezko ohea da, baita zabuak, hamakak eta dortoka-oskolak ere. 
- Entzumen-estimulazioa: saioa bideratzen ari den pertsonaren ahotsak gozoa eta atsegingarria izan behar du, gelaren baretasuna ezinbestekoa baita. Saioan erabili beharreko musikak leuna izan behar du, espresuki une horretarako aukeratutakoa eta paziente zehatz bati bideratutakoa, alegia. Zentzumen honen estimulazioan soinu-panelek, aulki musikalak, musika-kateak eta aire-zutabeak bezalako elementuek asko lagunduko dute.

- Usaimen-estimulazioa: zentzumen honen kitzikapenerako aromaterapia egiten da, non pazienteen eguneroko errutinarekin erlazionatutako usainak erabiliko baitira batez ere. Horrez gain, lurrin-barreiagailua eta usain-pilotak erabiliko dira aroma-joko ezberdinetan.

- Dastamen-estimulazioa: limoi baten garraztasunetik txokolatearen gozotasunera mingaineko dastamen-papilak kitzikatzen dituzten hainbat jaki edo elikagai erabiliko dira zentzumen honen kitzikapenerako.

- Propriozepzio-estimulazioa: Propriozepzioa entzumen-zentzumenarekin estuki erlazionatuta dagoen zentzua da. Propriozepzioa estimulatzeko erabiltzen diren elementu ohikoenak dardara-lastairak, dardara-zoruak, pilota-aulkia, pisudun burusiak eta puxtarri-igerilekuak dira.

1. irudia. Muskizko adinekoentzako eguneko zentroan Babesten taldeak kudeatzen duen Snoezelen gela. 1) aromaterapiako saioetan erabiltzen diren lurrinak; 2) ikusmen-zentzumena lantzeko ispilu-bola birakaria; 3) ukimen-zentzumena lantzeko eremua, non atal bakoitzean eskua sartuz, pazienteek, ehundura ezberdin bat ukitzeko aukera izango duten; 4) motrizitatearen koordinazioa garatzeko burbuila-tutuak; 5) bestibulu-estimulazioa lantzeko urezko ohea, eta 6) ikusmen-urritasuna eta sentikortasuna garatzeko ikusmen-zuntzak.

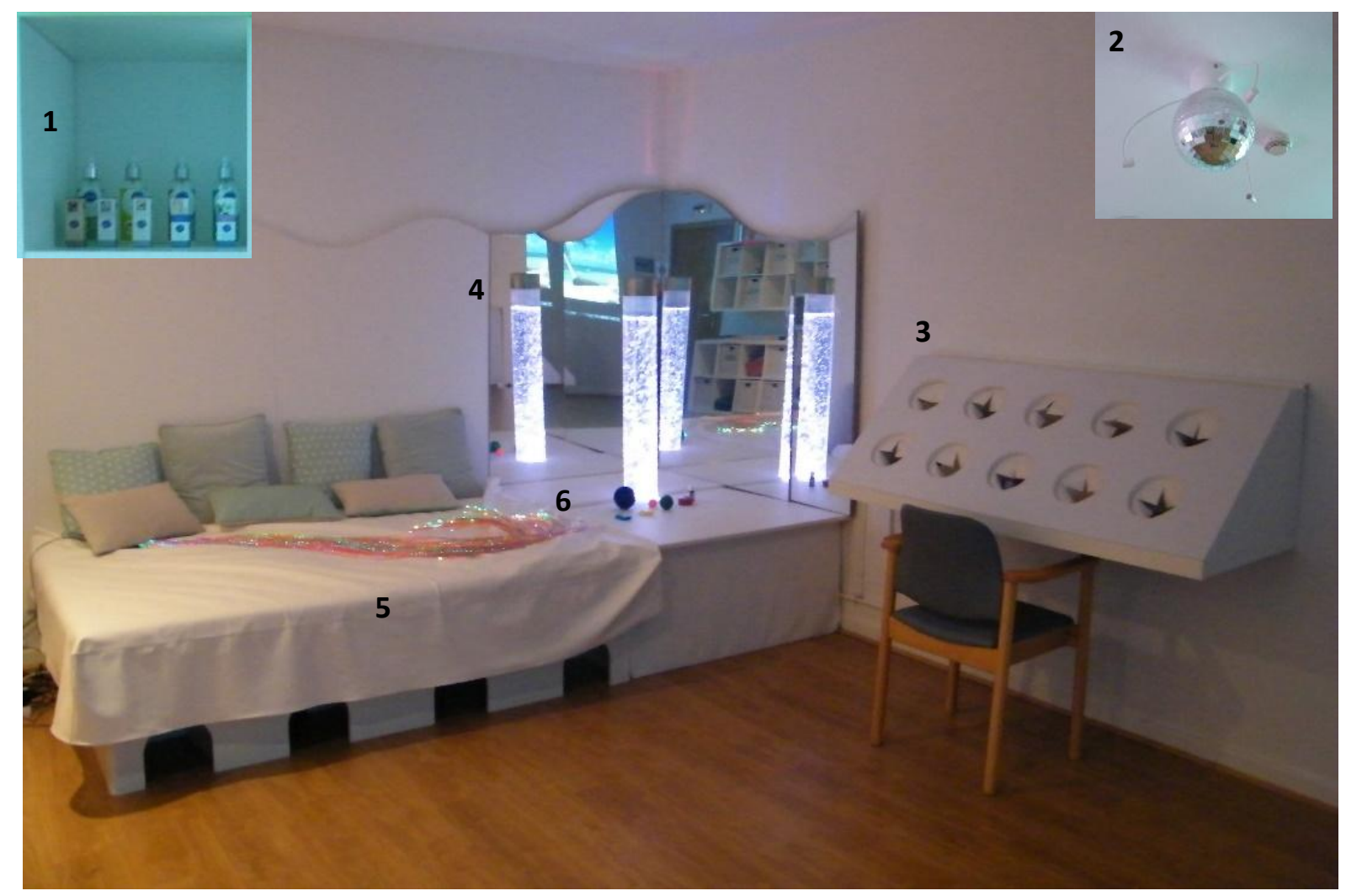

Snoezelen gelek bi erabilera nagusitara bideratuta daude: alde batetik pedagogikoa, eskoletan, enpresetan, haur-guneetan eta hezkuntza bereziko ikastetxeetan gauzatuko dena. Bestetik terapeutikoa, ospitaleetan, adinekoen egoitzetan, eguneko zentroetan eta mina artatzeko kliniketan egingo dena. Mota bakoitzean, beraz, berariazko jomuga ezberdinak landuko dira. 
1. taula. Snoezelen terapiaren erabilera pedagogikoan eta erabilera terapeutikoan jorratzen diren berariazko helburuak.

\begin{tabular}{|c|c|}
\hline SNOEZELEN PEDAGOGIKOA & SNOEZELEN TERAPEUTIKOA \\
\hline $\begin{array}{l}\text { Besteekiko harremanak hobetu } \\
\text { Sormenezko pentsaera eta gaitasuna bultzatu } \\
\text { Kontzentrazio- eta aditasun-denbora luzatu } \\
\text { Gizarte-trebetasunak garatu }\end{array}$ & $\begin{array}{l}\text { Segurtasun- eta erosotasun-sentsazioak sortu } \\
\text { Gizabanako bakoitzaren erlaxazioa bermatu } \\
\text { Pertsona-ingurumena elkarrekintza sustatu } \\
\text { Autokontrolaren kudeaketa eragin } \\
\text { Norberarenganako konfiantza garatu } \\
\text { Hizketa bidezko komunikazioa sustatu } \\
\text { Portaera-aldaketak saihestu } \\
\text { Gogo-aldartea orekatu } \\
\text { Oreka-jarduerei aurre egin ingurugiro segurua } \\
\text { ziurtatuz }\end{array}$ \\
\hline
\end{tabular}

ZATaren funtsa Holanda iparraldean kokaturik dagoen "De Hartenberg" Institutuan erabili eta ezarri zuten Ad Verheul eta Jan Hulsegge terapeutek estreinakoz (1). Orduko hartan, Snoezelen emozioetan oinarritutako terapia-multzo baten partetzat jotzen zen, eta xedea, batik bat, oinarrizko ikaskuntzaprozesuetan desgaitasun nabarmena zuten gaixoen ongizatean ardaztu zen; baita eguneroko ohiko zereginak egiteko zailtasunak adierazten zituzten pazienteen erlaxazioan ere (1). Geroztik, Europako hainbat herrialdetara, Estatu Batuetara, Kanadara, Australiara eta Asiako herrialdeetara hedatu zen. Denbora aurrera joan ahala, ZATaren erabilera klinikoa dementzia pairatzen zuten erien zainketara bideratu eta barreiatu zen batez ere (7). Gaur egun, dementziarako terapia ez-farmakologiko multzoaren barruan, Snoezelen terapiak B gomendatze-gradua lortu du (8).

\section{Snoezelen terapiaren saio batean bideratzen diren ariketa-ereduak}

Snoezelenen terapian parte hartuko duen paziente bakoitzaren gustua, gogoa, nahia edota zentzumen-lehentasunak ezberdinak dira. Hori dela-eta, saioa bideratzen duen pertsonaren lana da aldez aurretik ezagutzea paziente bakoitzaren lehenespenak. Horrela, estimulu desatseginak saihestuko dira eta norbanakoaren ongizatea bermatuko da saio bakoitzean.

- Motrizitate fina lantzeko ariketa: pazienteari ikusmen-zuntz sorta emango zaio. Helburua: sorta osatzen duen zuntz bakoitza, pixkanaka eta banan-banan bereiztea.

- Motrizitatearen koordinazioa lantzeko ariketa: azkenengo zuntza eskuan gordeta pazientea burbuila-tutura hurbilduko da. Helburua: burbuila-tutuan murgilduta dagoen eta mugimenduan dagoen objektuari ikusmen-zuntzarekin jarraitzea. Pazienteak ikusmen zuntza bertikalki eta horizontalki mugituko du, objektuaren norabidera moldatuz.

- Oroipenak lantzeko: pazientearentzat esanguratsua den usain baten bitartez oroitzapenak landuko dira. Musikaren bidez, helburu bera landu ahal da. Pazientearentzat esanguratsua den abesti baten bitartez oroitzapenak landuko dira eta abestera animatuko da. Jarraian, abesti bera jarriko zaio letra gabe. 
- Oroimena lantzeko ariketa: "Hitzak sortzeko testa" delakoan pazienteari hizki bat proposatuko zaio eta hizki horrekin hasi beharreko talde edo multzo bat aurkeztuko zaio. Adibidez E hizkia eta animaliak.

- Amaitzeko, erlaxazio-ariketa bat bideratuko da.

\section{Snoezelen terapiaren eragina dementzian}

Dementzia gaixotasun aurrerakorra, kronikoa eta suntsitzailea da (9). Gaur egun 46,8 milioi pertsona inguru bizi dira dementziaren mende; eta urtero, mundu osoan zehar, 9,9 milioi kasu berri diagnostikatzen dira (10). Hori gutxi balitz, Nazioarteko Alzheimer Erakundeak, 20 urterik behin, zenbaki horien bikoizketa esponentziala iragarri du. Horrela, 2050. urtearen amaieran, gutxi gorabehera, 131,5 milioi pertsonak dementzia pairatuko dute (11).

Dementziak oroimena, adimena, orientazioa, ulermena, ikas-ahalmena eta hizkuntza kaltetzen ditu (12), hots, gaitasun kognitiboak. Horrez gain, hain ezagunak ez diren sintoma fisikoen, fisiologikoen eta portaera-aldaketen eragile da (13). Portaera-aldaketen artean depresioa, psikosia, oldarkortasuna, motrizitatearen koordinazioaren galera (dementzia pairatzen duten gaixoak osasuntsuak dauden pertsonak baino hiru aldiz gehiago behaztopatzen dira), gogogabetasuna (14), suminkortasuna (15), antsietatea, urduritasuna, loezina, elikadura-nahasmendua eta gogo-aldarte gabezia izan dira pazienteek deskribatutako eta aintzat hartu beharreko sintoma aipagarrienak (16). Horren harira eta adituen aburuz, adineko pertsonek pairatzen eta deskribatzen dituzten portaeraaldaketa ohikoenak usadiozko adinekoentzako egoitzetan bizi duten bakartasunari, gelditasunari eta isolamenduari egotz dakizkieke, bertako zentzumen-gabetze nabaria dela-eta (17). Izan ere, egiaztatuta dago adineko pertsonen \%97ren bizi-kalitatea esanguratsuki okerrera joaten dela adinekoen etxeetan barneratu ondoren, hots, instituzionalizatu ostean (18). Gizakion zahartzea eta pixkanakako bost zentzumenetan bistaratutako narriadura zuzenki proportzionalak eta aldi berean gertatzen diren bi prozesu paralelo dira. Hala ere, dementzia dela kausa, pazienteen zentzumenek dituzten eraldaketak, argitzeke daude oraindik (11). Nolanahi ere, badirudi gaixo hauei, dementziaren eraginagatik, ikusteko, entzuteko, dastatzeko, sentitzeko eta usaintzeko duten interpretazio modua zeharo aldatzen zaiela (11).

2. irudia. Snoezelen kontzeptuaren parte diren osagaien laburpen eskematikoa.

"Snuffelen"= sentitu eta "Doezelen" = erlaxamendua, hain zuzen ere.

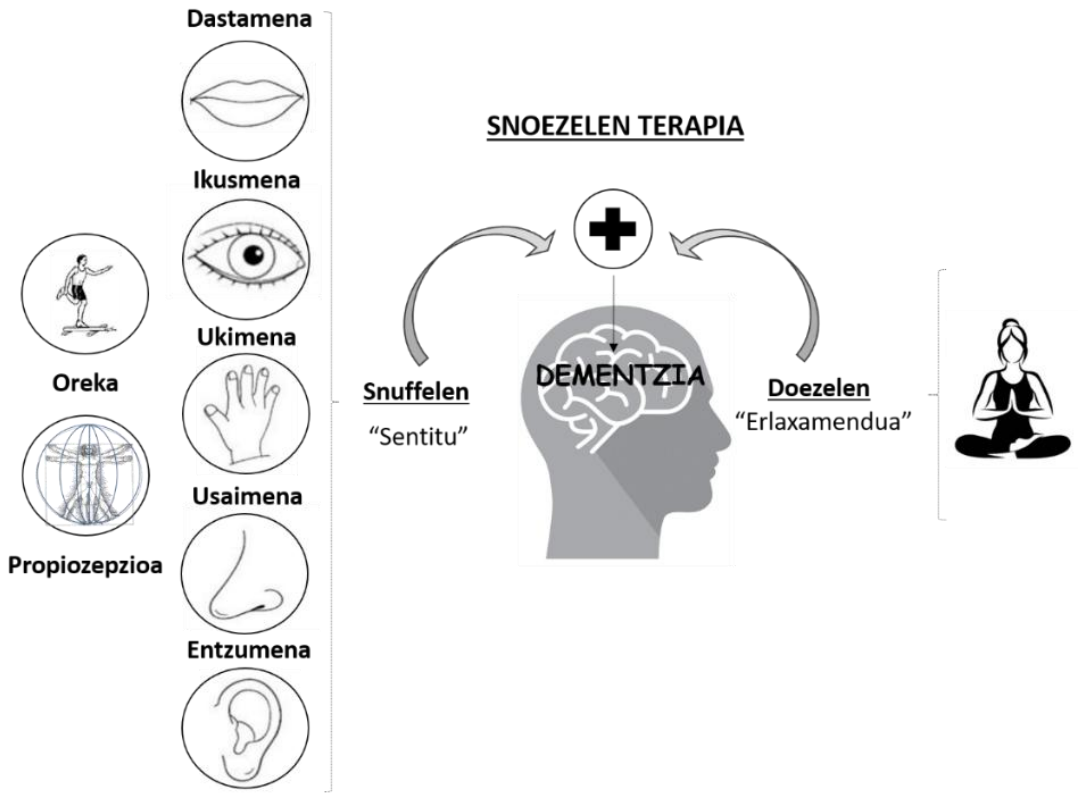


Dementziaren tratamendurako erabiltzen diren neuroleptikoek dakartzaten albo-ondorioak direlaeta, terapia psikosozialen esku-hartzea gero eta adierazgarritasun handiagoa eskuratzen joan da (19). Testuinguru horretan, azken 20 urteetan, Snoezelenen ingurugiro ez-farmakologikoen erabilera terapia psikosozialaren barnean sartzen dena- ospea lortzen joan da, batez ere dementzian erdietsitako ebidentzia zientifikoei esker (11). Izan ere, dementzian, ZAT barne-barneko estrategia eraginkor eta banakotzat hartzen da, non pazienteek, prozesu ulergarri eta atsegingarri baten bitartez, afektu eta zentzumen-mundua berraurkitzen duten, beren komunikazio-trebetasuna eta emozio-osasuna hobetuz (20). Azken urteotako ikerketen arabera Snoezelen gelek bat-bateko efektu mesedegarri eta onuragarriak eragiten dituzte dementzia pairatzen duten pazienteetan, lankonpromisoa suspertuz (21), artegatasuna murriztuz (22), bihotz-erritmoa gutxituz (23), minaren pertzepzioa kudeatuz (24), gizarte-elkarrekintza bultzatuz (21), aurre egiteko gaitasuna sustatuz (21), elikagaiekiko normaltasuna berreskuratuz (11) eta gogo-aldartea zoriontasunera bideratuz (22), besteak beste. Horrez gain, aurreratze esanguratsua antzeman da gaixoen hizketa bidezko komunikazioan, baita hizketaz kanpoko komunikazioan ere (25). Zentzu horretan, eta terapia honi esker, erien ongizate pertsonalak eta bizi-kalitateak nabarmenki hobera egin dute (21). Snoezelen ZAT ikuspegiak nerbio-sistema zentralean eragiten du. Horrela, kortexeko sare-antolaketa funtzionala aldatu eta pazienteak erlaxazio sakoneko egoera batean barneratzen dira (26).

\section{Snoezelen terapiaren eragina beste hainbat gaixotasunetan}

Nahiz eta azkenengo hamarkadan Snoezelen terapia dementzia gaixotasunaren osaketara bideratuta egon, hainbat ikerketak terapia honen erabilera beste gaitz bazuen hobekuntzarako tresna baliagarri gisa frogatu eta egiaztatu dute.

$>$ Rett sindromean, Snoezelen terapiak pazienteen motibazioa pizten duten 2 oinarrizko faktore eskaintzen ditu: musikaren maitasuna eta hurreko gizakien ukipena. Bi faktore horien sustapenari esker, gaitz honen mende bizi diren erien bizi-kalitatea zeharo hobetzen dela egiaztatu da. Rett sindromea pairatzen duten pertsonek sistema sinpatiko hiperaktiboa izateko joera dute (27), urduritasun-egoera iraunkor bat epe luzean mantenduz. Snoezelenek, hortaz, etengabeko erlaxazio-egoera batean barneratzen ditu pazienteak, pertsona bakoitzaren ongizatea bermatuz (28).

$>$ Terapia ez-farmakologiko honen onurak ere garunaren lesio traumatikoan berretsi dira. Snoezelen terapiak goiko eta beheko gorputz-adarretako muskuluen tonua modu esanguratsuan murrizten du, espasmo maila gutxituz eta pertsonen berezko egoera fisiologikoa berrezarriz. Horrez gain, terapia hau erabiltzen den bitartean, pazienteen bihotzerritmoaren eta aztoramen mailaren jaitsiera ere deskribatuak izan dira. Haatik, Snoezelenek garunaren lesio traumatikoan eragiten dituen onuren eraginkortasuna ez da denboran zehar mantentzea lortu (29).

$>$ Ingurugiro eta gela berezi hauek min kronikoan (30) eta zainketa aringarrietako programetan ere oso erabiliak eta baliagarriak izan dira, batez ere gaixotasun terminal baten diagnosia jaso ostean pazienteetan areagotzen den antsietate maila berrezartzeko xedearekin. Izan ere, berri txarra jasotzen duten eriek, Snoezelen saioen eraginkortasuna dela bide, ez dute antsietatea tratatzeko farmakoen beharrik izaten. Ikerketa hauen emaitza argitaratu eta gero, hainbat herrialdetan zainketa aringarrietara bideratuta dauden zentroek interes nabarmena izan dute, gela berezi hauek euren pazienteen ongizatean eta bizi-kalitate mailan ekar dezaketen onurak bultzatuta. Hala ere, aditu askoren aburuz, eta etorkizunari begira, terapia honen fidagarritasuna ziurtatzen duten ebidentzia enpiriko eta ikerketa gehiago beharko liratekeela uste da (31).

> Garun-paralisian Snoezelen terapiaren esku-hartzea ere baikorra bistaratu da. Alde batetik, arnasketaren fisioterapia hobetzen du, pazienteek isuritako lerdea murrizten du eta irensketa-ahalmena sendotzen du. Bestalde, terapia honetan hain bereizgarria den erlaxazio eta lasaitasun maila handiagotzen du, gurpil-aulkiko jarrera zeharo hobetuz eta gaitz honetan 
ager daitezkeen espasmoak modu esanguratsuan murriztuz. Hala eta guztiz ere, Snoezelen terapiaren eraginkortasuna garun-paralisian ez dela epe luzera mantentzen frogatu izan da (32).

> Terapia honen eragin positiboa haurrek eta nerabeek maiz izaten duten arreta-defizitaren eta hiperaktibitatearen nahasmenduan frogatu da. Hainbat patologia psikiatrikotan eta erditu berri diren emakumeek pairatzen dituzten gogo-aldarte aldaketetan ere frogatu da, erditu ondorengo depresio-indizeen murrizketa adierazgarria izan delarik $(33,34,35,36)$.

\section{Snoezelen terapiaren erabileraren egoera}

Gernikatik Gasteizera, Baionatik Iruñera, Muskiztik Donostiara, Barakaldotik Biarritzera... Snoezelen esparru ezberdinetan Euskal Herriko lau ertzetara eta lau haizetara zabaltzen ari den terapia berritzailea da, gaixotasun ezberdinen sintomatologia arintzeko hautabide eraginkorra bilakatzen ari den seinale.

3. irudia. Snoezelen terapiaren erabilera Euskal Herriko udalerri ezberdinetan

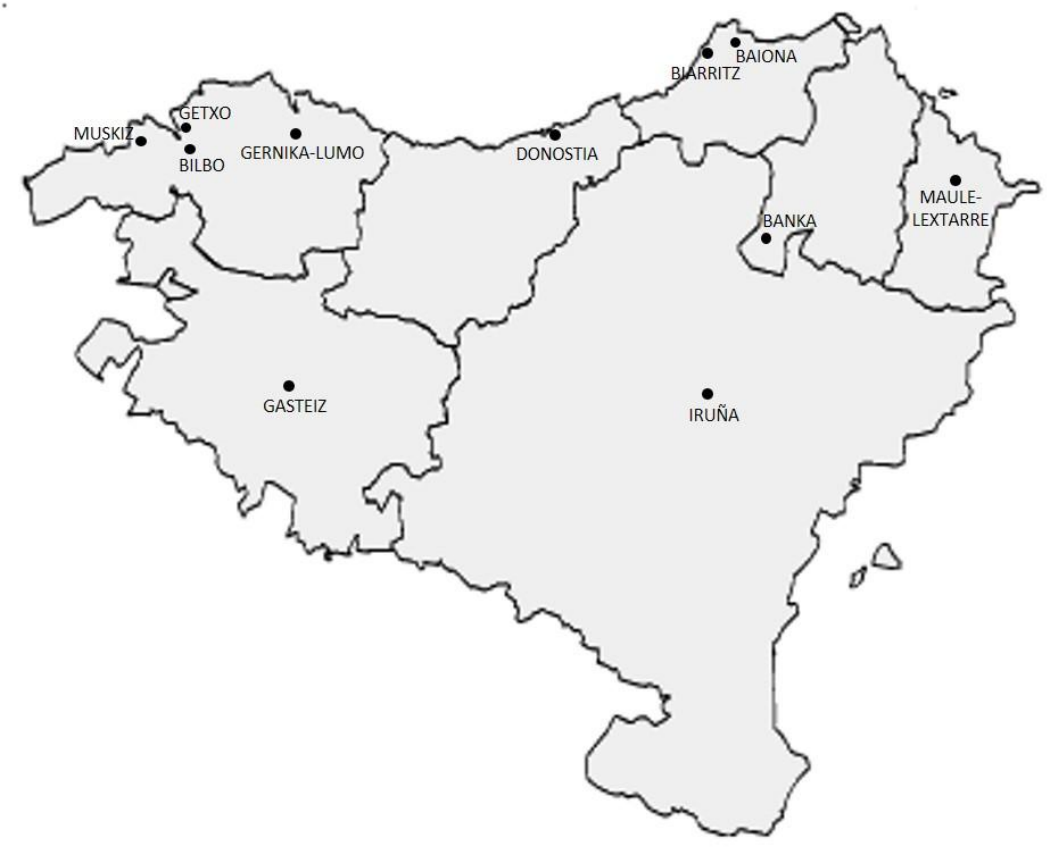

Gasteiz hiriaren kasuan, adibidez, 2014. urtean ohiko ikastetxe batean hasi ziren Snoezelen gelak aurrenekoz erabiltzen. Bertako langileak, hortaz, aitzindari bilakatu ziren teknika berri honen ezarketan. Helburuak: ikasleen ikas-ahalmenaren sustapena, nerabeen nerbio-sistemaren heltzea eta adingabeko gazteen garapenaren estimulazioan eragitea, besteak beste. Bestalde, badira Snoezelen terapia erabiltzen duten esparru ezagunagoak ere. Babesten taldeak kudeatzen duen Muskizko adinekoentzako eguneko zentroa, Iruñeko Amma Argaray adinekoen etxea edo Barakaldoko CIS gizarteratze-zentroa adibidez. Hiru kasu horietan adineko pertsonei zuzendutako zentzumen anitzeko terapia erabiltzen dute, eta ordura arte behatu eta jaso dituzten emaitzak zeharo betegarriak izan dira, bai pazienteentzat baita zaintzaileentzat ere. Izan ere, azken horiek ere, erlaxazio-saioetan parte har dezakete pazienteekin batera, egunerokotasunean jasaten duten estresa arintzeko eta oro har beren bizi-kalitatea hobetzeko.

Hedabideetan atera berri den azkenengo kasua dugu Biarritzen zabalduko duten eguneko zentro berritzailea. Alzheimer gaitzaren lehenengo etapan diren pertsonei zuzendutakoa izan da, hain zuzen ere. Eguneko edo asteko egonaldiak proposatuz, gaixoen egoera eta familia-zaintzaileen egunerokotasuna hobetzea da zerbitzuaren helburu nagusia. Berritasunen artean Snoezelen terapia abian jarriko dute, non pazienteen esperientzia sentsorialak 20 metro karratuko gela batean landuko diren. 
Hala eta guztiz ere, zentro berezi hauek ez dira adibide bakarrak. Maule-Lextarre, Donostia, Banka, Gernika-Lumo, Bilbo, Baiona edo Getxo bezalako herrietan ere Snoezelen terapiaren berri izan dugu azken urteotan, terapia honen hedapena aurrera abiatzen ari den seinale.

\section{Ondorioak}

Berrikuspen bibliografiko honek azken 15 urteetan Snoezelen terapiaren inguruan argitaratutako ikerketak, ikasketak, informazioa eta datuak biltzen ditu, kontzeptu horren ikuspegi orokor bat eskainiz.

Alde batetik, terapia honek eragiten dituen ahulguneak eta mugak errebisio bibliografikoan zehar islatzen dira. Berariazko bilatzaileetan nekez aurkitutako Snoezelenen ikerketa eskasek eta ebidentzia enpirikoen gabeziak fidagarritasunik eza dakarte berekin, terapia honen inguruan ikasketa gehiago egin beharraren premia agerian utziz.

Horrez gain, berrikuspen bibliografiko honetan zehar hainbat gaixotasunetan deskribatua izan den bezala, Snoezelen terapiaren eraginkortasuna ez da epe luzera mantentzen. Hori dela-eta, gela hauen eskuragarritasuna ezinbestekoa da, baita pazienteen engaiamendua eta motibazioa ere terapia honen inguruko egitarauetan jarraiki parte hartzeko.

Bestalde, terapia honek aurkezten dituen indarguneak azpimarratzen dira. Ongizatea, plazera, lasaitasuna, segurtasuna, erlaxazioa, bakea, zentzumenen estimulazioa... Norbanakoaren bizikalitatearen hobekuntza finean. Efektu onuragarri hauek guztiek esku-hartze osagarri aproposa bilakatzen dute Snoezelen terapia mediku espezialistek gaixotasun ezberdinak sendatzeko agindutako tratamendu farmakologikoen laguntzaile bezala aplikatuz, hain zuzen ere. Farmako ezberdinek gaixoen bizi-itxaropenaren luzapena eskaintzen dute. Snoezelen terapiak, berriz, gaixoetan azalera daitezkeen emozio edo sentimendu desatseginen kontrola mantentzen lagunduko du. Tratamendua/Snoezelen konbinazio hau, hortaz, gogobeteko elkarrekintza bat bezala aurreikusten da, egoera zaila eta sufrimendua pairatzen ari diren pazienteen bizi-kalitatea hobera egiteko aukera gisa.

\section{Erreferentzia bibliografikoak}

1. Lopez JJ, Bolívar JC, Perez MS. Assessment tool for reactions and behaviours of patients with dementia in a multisensory stimulation environment. Dementia (London). 2016; 15(4): 526538.

2. Collier L, Jakob A. The Multisensory Environment (MSE) in Dementia Care: Examining Its Role and Quality From a User Perspective. 2017; 10(5): 39-51.

3. Kaplan H, Clopton M, Kaplan M, Messbauer L, McPherson K. Snoezelen multi-sensory environments: task engagement and generalization. 2006; 27(4): 443-455

4. Maseda A, Sánchez A, Marante MP, González-Abraldes I, de Labra C, Millán-Calenti JC. Multisensory stimulation on mood, behavior, and biomedical parameters in people with dementia: is it more effective than conventional one-to-one stimulation?. Am. J. Alzheimers Dis. Other Demen. 2014; 29(7): 637-647.

5. Poza J, Gómez C, Gutiérrez MT, Mendoza N, Hornero R. Effects of a multi-sensory environment on brain-injured patients: assessment of spectral patterns. Med. Eng. Phys. 2013; 35(3): 365-375. 
6. Kwok HW, To YF, Sung HF. The application of a multisensory Snoezelen room for people with learning disabilities-Hong Kong experience. Hong Kong Med. J. 2003; 9(2): 122-126.

7. Baker R, Bell S, Baker E, Gibson S, Holloway J, Pearce R, Dowling Z, Thomas P, Assey J, Wareing LA. A randomized controlled trial of the effects of multi-sensory stimulation (MSS) for people with dementia. Br. J. Clin. Psychol. 2001; 40(1): 81-96.

8. Livingston G, Johnston K, Katona C, Paton J, Lyketsos CG. Systematic review of psychological approaches to the management of neuropsychiatric symptoms of dementia. Am. J. Psychiatry. 2005; 162(11): 1996-2021.

9. van Weert JC, van Dulmen AM, Spreeuwenberg PM, Ribbe MW, Bensing JM. Behavioral and mood effects of snoezelen integrated into 24-hour dementia care. J. Am. Geriatr. Soc. 2005; 53(1): 24-33.

10. Prince M, Wimo A, Guerchet M, Ali G-C, Wu Y-T, Prina M. World Alzheimer Report 2015. The Global Impact of Dementia. An Analysis of Prevalence, Incidence, Cost and Trends. Alzheimer's Disease International, London, 2015.

11. Strøm BS, Ytrehus S, Grov EK. Sensory stimulation for persons with dementia: a review of the literature. J. Clin. Nurs. 2016; 25(13-14): 1805-1834.

12. World Health Organization. Dementia: A Public Health Priority. (9789240689848).2012; World Health Organization, Geneva.

13. Cerejeira J, Lagarto L, Mukaetova-Ladinska EB. Behavioral and psychological symptoms of dementia. Front. Neurol. 2012; 3: 73.

14. Lawlor B, Bhriain SN. Psychosis and behavioural symptoms of dementia: defining the role of neuroleptic interventions. Int. J. Geriatr. Psychiatry. 2001; 16(Suppl 1): S2-S6.

15. Bergh S, Engedal K, Røen I, Selbæk G. The course of neuropsychiatric symptoms in patients with dementia in Norwegian nursing homes. Int. Psychogeriatr. 2011; 23(8): 1231-1239.

16. Finkel Sl. Behavioral and psychological symptoms of dementia: a current focus for clinicians, researchers, and caregivers. J. Clin. Psychiatry. 2001; 62(Suppl 21), 3-6.

17. MacDonald, C. Back to the real sensory world our 'care' has taken away. Journal of Dementia Care. 2002; 10: 33-36.

18. Buettner LL, Lundegren $H$, Lago $D$, Farrell $P$, Smith $R$. Therapeutic recreation as an intervention for persons with dementia and agitation: An efficacy study. Am. J. Alzheimers. Dis. 1996; 11: 4-12.

19. Kolanowski A, Fick D, Frazer C, Penrod J. It's about time: use of nonpharmacological interventions in the nursing home. J. Nurs. Scholarsh. 2010; 42(2): 214-222.

20. Baillon S, van Diepen E, Prettyman R. Multi-sensory therapy in psychiatric care. Adv. Psychiatr. Treat. 2002; 8: 444-452.

21. Collier L, McPherson K, Ellis-Hill C, Staal J, Bucks R. Multisensory stimulation to improve functional performance in moderate to severe dementia-interimresults. Am. J. Alzheimers Dis. Other Demen. 2010; 25(8): 698-703.

22. Moffat N, Barker P, Pinkney L, Garside M, Freeman C. 'Snoezelen ${ }^{\circledast}$ : an experience for people with dementia'. Chesterfield: Rompa; 1993.

23. Hotz GA, Castelblanco A, Lara IM, Weiss AD, Duncan R, Kuluz JW. Snoezelen: a controlled multi-sensory stimulation therapy for children recovering from severe brain injury. Brain. Inj. 2006; 20: 879-888

24. Scholfield, P. Snoezelen: Its potential for people with chronic pain. Complement Ther. Nurs. Midwifery. 1996; 2(1): 9-12.

25. van Weert JCM, van Dulmen AM, Spreeuwenberg PMM, Ribbe MW, Bensing JM. Effects of snoezelen, integrated in $24 \mathrm{~h}$ dementia care, on nurse-patient communication during morning care. Patient. Educ. Counsel. 2005; 58(3): 312-326.

26. Teplan M, Krakovská A, Stolc S. EEG responses to long-term audio-visual stimulation. Int. J. Psychophysiol. 2006; 59(2):81-90. 
27. Engerstrom IW, Kerr A. Workshop on autonomic function in Rett Syndrome, Swedish Rett center, Frösön, Sweden. Brain Dev. 1998; 20(5): 323-326.

28. Lotan M. Management of Rett syndrome in the controlled multisensory (Snoezelen) environment. A review with three case stories. ScientificWorldJournal. 2006; 791-807.

29. Hotz GA, Castelblanco A, Lara IM, Weiss AD, Duncan R, Kuluz JW. Snoezelen: a controlled multi-sensory stimulation therapy for children recovering from severe brain injury. Brain. Inj. 2006; 20(8): 879-888.

30. Schofield P, Davis B. Sensory stimulation (snoezelen) versus relaxation: A potential strategy for the management of chronic pain. Disabil. Rehabil. 2000; 22(15): 675-682.

31. Schofield P, Payne S. A pilot study into the use of a multisensory environment (Snoezelen) within a palliative day-care setting. Int. J. Palliat. Nurs. 2003; 9(3): 124-130

32. Velasco AC, Muñoz JE. Tratamiento fisioterápico del paralítico cerebral en sala Snoezelen. Fisioterapia. 2004; 26(3): 134-142.

33. Gonet $M$, Lenoel $M$. Apaiser et reconstruire par la communication sensorielle [le travail en espace snoezelen avec des patients psychotiques]. Revue de l'infirmière. 2008; 57: 20-21.

34. LeBel J, Stromberg N, Duckworth K, Kerzer J, Goldstein R, Weeks M, Harper G, LaFlair L, Sudders $M$. Child and adolescent inpatient restraint reduction: A state initiative to promote strength-based care. J. Am. Acad. Child. Adolesc. Psychiatry. 2004; 43(1):37-45.

35. Teitelbaum A, Volpo S, Paran R, Zislin J, Drumer D, Raskin S, Katz G, Shlafman M, Gaber A, Durst R. Multisensory environmental intervention (snoezelen) as a preventive alternative to seclusion and restraint in closed psychiatric wards. Harefuah. 2007; 146 (1): 11-80.

36. Hauck YL, Summers L, White E, Jones Ch. A qualitative study of Western Australian women's perceptions of using a Snoezelen room for breastfeeding during their postpartum. International Breastfeeding Journal. 2008: 3(20):1-9. 